\title{
Glasgow Meeting of the Society of Chemical Industry.
}

$\mathrm{T}$ HE forty-first annual meeting of the Society of Chemical Industry, which was held in Glasgow on July 4-II, was the fourth occasion on which the Society has visited Glasgow, the last visit being in rgro. Last year the Society met in Canada, under the presidency of Sir William Pope, and at this year's meeting it has been honoured by the presence of its Canadian president, Prof. R. F. Ruttan, of McGill University, Montreal, with a party of visitors from Canada and the United States.

The president addressed the Society on "Some Aspects of Scientific and Industrial Research," and, after referring to the influence of the war in directing academic research into industrial channels, spoke of the lesson of co-operation which had thereby been learned, and the prominence now being given to internationalism in science. This was expressed notably in the establishment at Brussels in I9r9 of the International Research Council of the Allied and Neutral Nations. The Council includes the International Union of Pure and Applied Chemistry, and its ultimate goal is to make a World Parliament of Sciences. This organisation, said the president, should do more than any other for the unification of mankind, because its underlying principle is the universalism of science and the catholicity of truth. The organisation in Great Britain of a State Department of Scientific and Industrial Research has given rise to similar Departments in the Overseas Dominions and the United States. In consequence, a dearth has been revealed of men sufficiently trained and laboratories suitably equipped for research. One of the first problems to be faced by the research organisations is how permanently to associate those pursuing abstract science with those concerned with its application. Universities must be regarded as holding their laboratories and equipment in trust for the community; and they are responsible for inculcating the principles and habits of work which underlie all research. The countries of the Empire expect capacity for research from the scientific departments of their universities, and the universities must therefore have adequate State aid to discharge these responsibilities. Further, Prof. Ruttan advocated the establishment of a Stateaided Research Institute in Great Britain, where future scientific and industrial research would be suitably blended. A compromise must be made between scientific ideals and industrial needs; and scientific research should become an accepted responsibility of the State, as certain and permanent as that of national education.

A noteworthy feature of the present meeting has been the inauguration of the Messel Memorial Lectures, established by means of a legacy to the Society of Chemical Industry by the late Dr. Rudolph Messel, which was to beapplied for " . . . the furtherance of scientific research and such other suitable objects as the Council of the Society may determine." The first Messel Medal was presented to Prof. H. E. Armstrong, who delivered a lecture entitled " Rhapsodies culled from the Thionic Epos.'

The title of Prof. Armstrong's lecture is explained by the fact that Dr. Messel was the pioneer in the manufacture of sulphuric anhydride by the aid of a platinum catalyst. Besides discussing the mechanism of catalysis and the influence of water in chemical. change, the lecturer made an earnest plea for clear thinking in science, for free criticism and exchange of opinion, and for the development of a philosophy of science based on experience. Prof. Armstrong said he was glad that, after the great attention which had been paid to the physical aspects of chemistry, a return was now being made to the consideration of molecular structure, and the inner meaning of chemical phenomena. Advance in the domain of organic chemistry has outstripped that in other branches, because in them there had been little effort to develop a theory of chemical change on the foundation laid by Faraday.

Papers were read by Dr. J. W. M'David on "A Rapid and Accurate Method for the Calibration of Storage Tanks," a method which depends on the time taken to fill the tank to a given level by water forced through an orifice by a constant head; and by Dr. R. A. Joyner on "The Viscosity of Cellulose in Cuprammonium Hydroxide," a novelty described being the preparation of the reagent by dissolving finely divided copper in aërated ammonia solution.

The remaining papers of scientific interest were provided by the Engineering Group, which, in its fifth conference under the chairmanship of Mr. J. A Reavell, considered the subject of evaporation and distillation

In an introduction to an abstract of the papers the relation between evaporation and distillation with reference to modern types of plant was emphasised. Mr. P. Parrish presented a paper on the design of ammoniacal liquor stills, in which the origin of the present type of still was traced, details of the composition of ammoniacal liquor were given, and the distinguishing features of the various kinds of still were discussed, together with the physico-chemical principles involved in their use, and the probable lines of future development. Mr. W. A. Walmsley dealt with tar distillation. In this paper the differences in composition between tar from horizontal and from vertical retorts were considered, and details were given of experiments on the continuous distillation of tar, which yields a greater output than the intermittent process. The treatment of tar fractions was outlined, experiences with modern distilling columns were described, and lines of desirable progress suggested.

The general problem of evaporation was reviewed by Prof. J. W. Hinchley. The influence of various conditions of temperature, atmospheric pressure, and hygroscopic state, radiation, and air-contact upon evaporation was considered. Appropriate evaporation formulæe were developed, their application to details of engineering design was discussed, and their economic importance emphasised. Mr. T. H. Gray read a paper on the historical development of the distillation of glycerine in which interesting drawings of plant were submitted. The importance of economic working was pointed out and the high state of purity of the modern product emphasised. The value of all these papers was much enhanced by the discussions by which they were followed.

A handbook of the meeting had been prepared by the local secretary, Dr. J. A. Cranston, which contained a useful account of the chemical and allied industries of Glasgow and the West of Scotland, prepared by Mr. W. H. Coleman. R. M. C. 